\title{
In vitro analysis of the influence of surface treatment of dental implants on primary stability
}

\section{Carla Rodrigues Mazzo(a) Andréa Cândido dos Reis ${ }^{(b)}$ Antonio Carlos Shimano(c) Mariana Lima da Costa Valente ${ }^{(a)}$}

(a) School of Dentistry of Ribeirão Preto, University of São Paulo - USP, Ribeirão Preto, SP, Brazil.

(b) Department of Dental Materials, School of Dentistry of Ribeirão Preto, University of São Paulo - USP, Ribeirão Preto, SP, Brazil.

(c)Department of Biomechanics and Orthopaedics, School of Medicine of Ribeirão Preto, University of São Paulo USP, Ribeirão Preto, SP, Brazil.
Declaration of Interests: The authors certify that they have no commercial or associative interest that represents a conflict of interest in connection with the manuscript.

Corresponding author:

Andréa Cândido dos Reis

E-mail: andreare73@yahoo.com.br

Received for publication on Sep 29, 2011 Accepted for publication on Mar 26, 2012

\begin{abstract}
Surface treatment interferes with the primary stability of dental implants because it promotes a chemical and micromorphological change on the surface and thus stimulates osseointegration. This study aimed to evaluate the effects of different surface treatments on primary stability by analyzing insertion torque (IT) and pullout force (PF). Eight samples of implants with different surface treatments (TS - external hexagon with acid surface treatment; and MS - external hexagon, machined surface), all $3.75 \mathrm{~mm}$ in diameter $\times 11.5 \mathrm{~mm}$ in length, were inserted into segments of artificial bones. The IT of each sample was measured by an electronic torquemeter, and then the pullout test was done with a universal testing machine. The results were subjected to ANOVA $(\mathrm{p}<0.05)$, followed by Tukey's test $(\mathrm{p}<0.05)$. The IT results showed no statistically significant difference, since the sizes of the implants used were very similar, and the bone used was not highly resistant. The PF values $(\mathrm{N})$ were, respectively, TS $=403.75 \pm 189.80$ and MS $=276.38 \pm 110.05$. The implants were shown to be different in terms of the variables of maximum force $(\mathrm{F}=4.401, \mathrm{p}=0.0120)$, elasticity in maximum flexion $(\mathrm{F}=3.672$, $\mathrm{p}=0.024)$, and relative stiffness $(\mathrm{F}=4.60, \mathrm{p}=0.01)$. In this study, external hexagonal implants with acid surface treatment showed the highest values of pullout strength and better stability, which provide greater indication for their use.
\end{abstract}

Descriptors: Dental Implantation; Osseointegration; Tensile Strength; Torque.

\section{Introduction}

In the 1960 s, Brånemark ${ }^{1}$ discovered that titanium was biocompatible with bone and could attach to it. Since then, many studies have been conducted to determine the nature of the interaction that occurs between the metal and the tissue ${ }^{2-5}$ called osseointegration, in which the bone-implant unit becomes an anatomical structure ${ }^{6}$ and supports patient function without causing injury.

Currently, the dental implant is an object of study by several researchers $^{7-11}$ whose goals are to develop design innovations and application techniques to optimize the implant's physical-chemical and mechanical properties. ${ }^{7}$ One current area of research involves the treatment of implant surfaces for osseointegration stimulation due to a chemical or micromorphological alteration of the implant ${ }^{9}$ that can facilitate early in- 
stallation of the prosthesis. ${ }^{12}$

These innovations are designed to improve the technical conditions for implant insertion and improve osseointegration, which is possible only if primary stability of the implants is attained. Primary stability is defined as the resistance to micromovement of the implant in the surgical site immediately after its insertion, and is one of the main factors required for osseointegration, since stability facilitates the formation of bone cells around the implants. Primary stability is dependent on factors such as bone type, and on characteristics related to implants, such as design and surface topography. ${ }^{13}$

Primary stability of implants can be measured by the analysis of resonance frequency ${ }^{14}$ or through the pullout assay. ${ }^{15,16}$ Another property that must be considered is the implant's resistance to the forces to which it is subjected, such as the insertion technique, bone resistance, and chewing forces (in cases of immediate loading). Therefore, in vitro tests have been performed to evaluate the behavior of implants subjected to such forces. ${ }^{17}$ In these tests, it was observed that the implants with treated surfaces behaved differently than the machined implants. ${ }^{18,19}$

This study aimed to evaluate the insertion torque and the pullout resistance of titanium dental implants with treated and untreated surfaces before osseointegration, and to evaluate the effects of these treatments on primary stability.

\section{Materials and methods}

In this study, 16 cylindrical external hexagonal implants, measuring $3.75 \mathrm{~mm}$ in diameter $\times 11.5 \mathrm{~mm}$ in length (Conexão, Arujá, Brazil), were evaluated. They were divided into two groups of samples, one with treated surfaces (TS) and another with machined surfaces (MS). Each implant was inserted into a femur of synthetic material (Symbone, Malans, Switzerland), ${ }^{20,21}$ since artificial polyurethane bones have greater standardization of density, preventing the interference of this factor in the values of insertion torque and pullout resistance.

To obtain the portion of the synthetic femur with the desired characteristics, we sawed the upper portion of the femur just below where the implants were to be inserted. Next, we prepared an orifice for each implant using an electric motor under torque of $25 \mathrm{~N} / \mathrm{cm}$ and $1470 \mathrm{RPM}$ (revolutions per minute), following the bur sequence recommended by the manufacturer. The implants were then inserted vertically by means of a ratchet key, and the insertion torque was measured by an electronic torquemeter.

To verify pullout strength, we developed a shield that was welded to the slap implant and attached to a piece to adapt to the load cell. This device was fixed to the base of a universal testing machine (model Emic DL-10000; Emic - São José dos Pinhais, Brazil) through a circular hole.

The test was performed under a load cell of $200 \mathrm{kgf}$, and the results were collected with Tesc 3.13 software (Emic - São José dos Pinhais, Brazil). In addition to the values of maximum force (Fmax), we also obtained values for maximum deflection (Def max), relative stiffness (RS), and modulus of elasticity in maximum flexion (EF max).

At the end of the test, results were subjected to statistical ANOVA to detect statistically significant differences between and among the different implants tested. Statistically significant variables were subjected to multiple comparisons with Tukey's HSD test. The significance level was $5 \%$, and analysis was performed with SPSS Statistical Software, version 17 (SPSS, Chicago, USA).

\section{Results}

The medium insertion torques obtained were $11.39 \mathrm{~N} \mathrm{~cm}$ for the TS implants and $10.34 \mathrm{~N} \mathrm{~cm}$ for the MS implants. ANOVA showed that there was no significant difference $(\mathrm{p}<0.05)$.

The pullout resistance tests were performed with the dependent variables maximum pullout strength, Def max, RS, and EF max (Tables 1, 2, and 3).

The results obtained by the ANOVA tests (mul-

Table 1 - ANOVA.

\begin{tabular}{c|r|r|r|c}
\hline & Sum Square & Mean Square & $F$ & $P$ \\
\hline Fmax & 215529.89 & 71843.30 & 4.40 & 0.12 \\
\hline Def max & 0.14 & 0.05 & 0.92 & 0.44 \\
\hline EF max & 55689.01 & 18563.00 & 3.67 & 0.024 \\
\hline RS & 376284.34 & 125428.11 & 4.6 & 0.01 \\
\hline
\end{tabular}




\begin{tabular}{rc|c|c|c|c} 
Table 2 - Average values of \\
\cline { 2 - 7 } $\begin{array}{r}\text { maximum force, maximum } \\
\text { deformation, maximum relative } \\
\text { stiffness, and maximum EF } \\
\text { obtained for each implant. }\end{array}$ & Treated Surface & $403.7 \pm 189.8$ & $0.91 \pm 0.23$ & $198.77 \pm 102.37$ & $660 \pm 187.44$ \\
\cline { 2 - 8 } & Machined Surface & $276.38 \pm 110.05$ & $0.77 \pm 0.21$ & $123.91 \pm 62.95$ & $518.1 \pm 142$ \\
\hline
\end{tabular}

tivariate analysis of variance) showed significant differences between the two groups of implants in terms of pullout tests (Wilks' Lambda $=0.312$, $\mathrm{p}=0.001)$.

\section{Discussion}

Because of the great progress that has been made in the development of dental implants, these materials fill the market with different options regarding geometry, size, and surface characteristics. Given this variety, the dentist may choose an implant that favors rehabilitation, by increasing the surface available for bone-implant contact, and promotes good primary stability, osseointegration, and distribution of forces. ${ }^{22,23}$

However, this extensive range of available options can also generate doubts about the real advantages and benefits of each product.

With the aim of evaluating the insertion torque and pullout resistance of different implants, we opted to use synthetic bone, because its mechanical properties are similar to those of natural bones, except for trials involving twisting. ${ }^{20,21}$ During processing, synthetic bone showed uniformity in density and geometry, favoring a standard analysis of the variable types of bones.

Primary stability is undoubtedly one of the main factors required for the occurrence of osseointegration; however, changes in the shapes and types of implants in the quest to increase this stability can often lead to necrosis of the bone surface ${ }^{24}$ when the threshold of bone strength is crossed due to very high torque. In this study, when we measured insertion torque, there was no significant difference between the groups. It is believed that this is due to the lack of difference in diameter between the implants used.

Given the diversity of rehabilitation methods, mediated or delayed, a further difficulty may arise in the selection of the implant, since each requires
Table 3 - Means $( \pm S D)$ of pullout strength $(N)$ of implants $(\mathrm{n}=8)$.

\begin{tabular}{c|c|c}
\hline Implant & Pullout strength $(\mathrm{N})$ & p value \\
\hline Treated Surface & $403.7 \pm 189.8$ & 0.214 \\
\hline Machined Surface & $276.38 \pm 110.05$ & 0.214 \\
\hline
\end{tabular}

correlation of bone type, implant type, and primary stability.

Some paradigms exist wherein the implant surface treatment influences mainly the primary stability of implants. This study showed that surface treatment also influences primary stability, which is extremely positive, since the cylindrical implants with treated surfaces showed superior results of pullout strength compared with those with machined surfaces. This result suggests that the roughness caused by surface treatment increases the friction between the implant surface and bone, influencing primary stability. ${ }^{9} 18,19$ Moreover, when the surface treatment increased bone-implant contact, the likelihood of osseointegration increased. ${ }^{11}$ However, the high pullout resistance of implants with treated surfaces compared with those having machined surfaces suggests that the surface influences initial stability even when osseointegration does not occur.

It is suggested that the correlation between primary stability and pullout resistance is biomechanical, since the higher stability of the screw in the bones suggests that the pullout resistance of the same is greater. ${ }^{16}$

The results demonstrated the great efficiency of implants with treated surfaces, and the literature shows that treating implants with acids, as in the present study, leads to the formation of surface roughness, allowing for greater contact with osteoblastic cells. ${ }^{9,18,25}$

When pullout tests are performed, the implant should be completely vertical, so that its pullout re- 
sistance would be influenced only by the surrounding bone, since if the implant was inclined, part of the bone would be around the implant, resulting in a resistance higher than that obtained. To prevent this, we developed a shield with a circular hole with a diameter smaller than that of the upper portion of the femur, and fixed it to a universal testing machine in which the sample was positioned with the implant, so that, when pulled, the implant would be positioned as vertically as possible.

The pullout tests simply evaluated the screw resistance after the application of axial force, which does not correspond to physiological forces on the implant. This was the most practical way to eval-

\section{References}

1. Hagberg K, Brånemark R. One hundred patients treated with osseointegrated transfemoral amputation prostheses - rehabilitation perspective. J Rehabil Res Dev. 2009;46(3):331-44.

2. Brentel AS, Vasconcellos LMR, Oliveira MV, Graça MLA, Vasconcellos LGO, Cairo CAA, et al. Histomorphometric analysis of pure titanium implants with porus surface versus rough surface. J Appl Oral Sci. 2006 Jun;14(3): 213-8.

3. Castilho GAA, Martins MD, Macedo WAA. Surface characterization of titanium based dental implants. Braz J Phys. 2006 Sep;36(3):1004-8.

4. Gahlert M, Röhling S, Wieland M, Sprecher CM, Kniha $\mathrm{H}$, Milz S. Osseointegration of zirconia and titanium dental implants: a histological and histomorphometrical study in the maxilla of pigs. Clin Oral Implants Res. 2009 Nov;20(11):1247-53.

5. Gebran MP, Wassal T. Evaluation in vitro of the adhesion of osteoblasts on osseointegrated implant with treated surface (Titamax II ${ }^{\circledR}$ ). Implant News. 2007 Jan-Feb;4(1):79-84.

6. Fathi MH, Azam F. Novel hydroxiapatite/tantalum surface coating for metallic dental implant. Mater Lett. 2007 Feb;61(4-5):1238-41.

7. Citeau A, Guicheux J, Vinatier C, Layrolle P, Nguyen TP, Pilet $\mathrm{P}$, et al. In vitro biological effects of titanium rough surface obtained by calcium phosphate grid blasting. Biomaterials. 2005 Jan;26(2):157-65.

8. De Maetzu MA, Braceras I, Alava JI, Gay-Escoda C. Improvement of osseointegration of titanium dental implant surfaces modified with CO ions: a comparative histomorphometric study in beagle dogs. Int J Oral Maxillofac Surg. 2008 May;37(5):441-7.

9. Le Guéhennec L, Soueidan A, Layrolle P, Amouriq Y. Surface treatments of titanium dental implants for rapid osseointegration. Dent Mater. 2007 Jul;23(7):844-54. uate this variable, which is complex and, as mentioned before, is related to various factors such as bone quality and implant characteristics. ${ }^{26}$

\section{Conclusion}

The surface treatment of implants increases their primary stability. This suggests a greater indication for the use of surface-treated implants for oral rehabilitation and implantology.

\section{Acknowledgments}

This study was supported by the National Council for Scientific and Technological Development (Identification number: 149531/2010-9).

10. Li DH, Liu BL, Zou JC, Xu KW. Improvement of osseointegration of titanium dental implants by a modified sandblasting surface treatment: an in vivo interfacial biomechanics study. Implant Dent. 1999;8(3):289-94.

11. Sollazzo V, Pezzetti F, Scarano A, Piattelli A, Bignozzi CA, Massari L, et al. Zirconium oxide coating improves implant osseointegration in vivo. Dent Mater. 2008 Mar; 24(3): 35761.

12. Akça K, Chan TL, Tekdemir I, Fanuscu M. Biomechanical aspects of initial intraosseous stability and implant design: a quantitative micromorphometric analysis. Clin Oral Implants Res. 2006 Aug;17(4):465-72.

13. Amarante ES, Lima LA. [Optimization of implant surfaces: titanium plasma spray and acid-etched sandblasting-current state]. Pesqui Odontol Bras. 2002 Apr-Jun;15(2):166-73. Portuguese.

14. Kahraman S, Bal BT, Avsar NV, Turkyilmaz I, Tözüm TF. Clinical study on the insertion torque and wireless resonance frequency analysis in the assessment of torque capacity and stability of self-tapping dental implants. J Oral Rehabil. 2009 Oct;36(10):755-61.

15. Defino HL, Rosa RC, Silva P, Shimano AC, Volpon JB, De Paula FJ, et al. The effect of repetitive pilot-hole use on insertion torque and pullout strength of vertebral system screws. Spine (Phila Pa 1976). 2009 Apr;34(9):871-6.

16. Kim JW, Baek SH, Kim TW, Chang YI. Comparison of stability between cylindrical and conical type mini-implants. Angle Orthod. 2008 Jul;78(4):692-8.

17. Turkyilmaz I, Sennerby L, McGlumphy EA, Tözüm TF. Biomechanical aspects of primary implant stability: a human cadaver study. Clin Implant Dent Relat Res. 2009 Jun;11(2):1139 . 
18. González JMM, Sabán FG, Bernal JF, Lafuente JCG, Sánchez JC, Dorado CB. Removal torque and physico-quimical characteristics of dental implants etched with hydrofluoric and nitric acid. An experimental study in beagle dogs. Med Oral Patol Oral Cir Bucal. 2006 May;11(3):281-5.

19. Stüker RA, Teixeira ER, Beck JCP, Costa NP. Preload and torque removal evaluation of three different abutment screws for single standing implant restorations. J Appl Oral Sci. 2008 Jan-Feb;16(1):55-8.

20. Cristofolini L, Viceconti M, Capello A, Toni A. Mechanical validation of whole bone composite femur models. J Biomech. 1996 Apr;29(4):525-35.

21. Cristofolini L, Viceconti M. Mechanical validation of whole composite tibia models. J Biomech. 2000 Mar;33(3):279-88.

22. Hsu SH, Liu BS, Lin WH, Chiang HC, Huang SC. Characterization and biocompatibility of a titanium dental implant with a laser irradiated and dual-acid etched surface. Biomed Mater Eng. 2007 Jan;17(1):53-68.
23. Misch CE. Density of bone: effect on treatment plans, surgical approach, healing, and progressive bone loading. Int J Oral Implantol. 1990;6(2):23-31.

24. Lim SA, Cha JY, Hwang CJ. Insertion torque of orthodontic miniscrews according to changes in shape, diameter and length. Angle Orthod. 2008 Mar;78(2):234-40.

25. Langhoff JD, Voelter K, Schanweber D, Schnabelrauch M, Scholotting F, Hefti T, et al. Comparison of chemically and pharmaceutically modified titanium and zirconia implant surfaces in dentistry: a study in sheep. Int J Oral Maxillofac Surg. 2008 Dec;37(12):1125-32.

26. Ohta K, Takechi M, Minami H, Shigeishi H, Hiraoka M, Nishimura $\mathrm{M}$, et al. Influence of factors related to implant stability detected by wireless resonance frequency analysis device. J Oral Rehabil. 2010 Feb;37(2):131-7. 